\title{
ERRATUM
}

\section{Improvement of the surface state of a sandblasted glass by deposing a thin layer of $\mathrm{SiO}_{2}$ using sol-gel technique}

\author{
A. Marouani ${ }^{1}$, N. Bouaouadja ${ }^{1}$, A. Duran ${ }^{2}$ and Y. Castro ${ }^{2}$ \\ ${ }^{1}$ Laboratory of Non-Metallic Materials, I.O.P.M., F. Abbas University, Sétif 19000, Algeria \\ 2 Instituto de Ceramica y Vidrio (CSIC), Campus de Cantoblanco, 28049 Madrid, Spain
}

MATEC Web of Conferences 5, 04021 (2013)

DOI: $10.1051 /$ matecconf/20130504021

The name of the authors should be A. Marouani, N. Bouaouadja, A. Duran and Y. Castro instead of M. Abdelhak, B. Nourredine, D. Alicia and C. Yolanda. 